\title{
Cultural Attitudes towards Death Practices, the Body after Death and Life after Death in Deceased Organ Donation - A UK Polish Migrant Perspective
}

Sharp C and Randhawa G*

Professor, Director of the Institute for Health Research, University of Bedfordshire, UK

*Corresponding author: Randhawa G, Professor Gurch Randhawa, University of Bedfordshire, Putteridge Bury Campus, Hitchin Road, Luton, LU2 8LE, UK; Tel: 01582 743797; E-mail: gurch.randhawa@beds.ac.uk

Received date: May 04, 2016; Accepted date: May 17, 2016; Published date: May 21, 2016

Copyright: (c) 2016 Sharp C, et al. This is an open-access article distributed under the terms of the Creative Commons Attribution License, which permits unrestricted use, distribution, and reproduction in any medium, provided the original author and source are credited.

\begin{abstract}
Previous studies have found the perception of the body and death practices can have an influence on perceptions of deceased organ donation. This is the first study in the UK to investigate the views of the Polish migrants, a fast growing community, toward organ donation, death practices and the deceased body. In total, there were 31 participants that took part in the study in one-to-one interviews or small focus group interviews that lasted approximately $1 \frac{1}{2}$ hours. The majority were conducted in English and 1 focus group and 7 interviews were in Polish. The interviews were recorded with permission from the participant, transcribed and analysed using grounded theory analysis. Participants believed the body was seen to be useful for others in need of organs after the individual had died. Families were thought to struggle with saying 'goodbye' if it was perceived the deceased individual was to 'live on' in the recipient. Participants highlighted that within Polish culture, funerals were organised quickly and opencasket burials were common, however these practices would not hinder donation. Being aware of this community's perspective may aid healthcare professionals when discussing deceased organ donation with potential donor families.
\end{abstract}

Keywords: Body; Death practices; Deceased organ donation; Polish migrant; UK

\section{Introduction}

Currently, the demand for transplantable organs far outstrips supply and this gap is ever widening. This is a marked issue for minority ethnic groups. African-American, Black African, Black Caribbean and South Asian populations in the USA and UK are under-represented on the organ donor register and over-represented on the transplant waiting list due to the susceptibility to End Stage Renal Failure [1].

Deceased organ donation is part of end-of-life choices that individuals may make about what happens to their body after death. It can be a decision that a family makes about their relative and whether his or her organs are donated after death. As organ donation is tied to death that in itself is influenced by culture and religion. In turn perceptions on the need for the body after death, death rituals and practices and the notion of the connectivity between the body and the 'self' after death can impact upon organ donation decisions.

\section{Cross-cultural views toward death in deceased organ donation}

The gap between life and death are socially and culturally constructed and the definition of death itself is culturally and legally defined. In deceased organ donation, there are two ways in which death is defined; brain stem death for Donation after Brain Death (DBD) or circulatory death for Donation after Circulatory Death (DCD). There is huge variation across countries with transplant programmes in the definition of death in organ donation in organ transplantation policy.
Bowman and Richard [2] suggest in Western culture, death is a 'unitary phenomenon' (p.213) where the definition of brain death is based on scientific principles but Western medicine is socially constructed, principally influenced by the desire to plan and control life events [2]. In the West, Christianity has shaped how the body and soul are perceived where the body is respected after death but the body is no longer viewed as a person without a soul. For organ donation, Christian tenets support the non-reciprocal nature of giving in organ donation and may contribute toward the acceptance of organ donation. Brain death is viewed as acceptable in Western medicine as the mind departs from the body upon death and this separation defines the death of a human being [2]. Therefore, the notion of death and the perception of the separation of the body and mind upon death in addition to the Christian construct of giving have shaped the social and cultural norms of organ donation in the West. The social and cultural construction of Western medicine and views toward the body upon death may also have influenced organ donation policy. The UK uses both Donation after Circulatory Death (DCD) and Donation after Brain Death (DBD) and has become the leading country in the development of controlled DCD and around half of deceased donors are DCD. Not all countries use both forms of diagnosis of death for donation.

In Japan, Bowman and Richard [2] outline the complexities of using brain death as a diagnosis of death. In Japan, cultural and religious constructs of death are influenced by Shinto, Buddhism and Confucianism and Japanese society favours 'natural' approaches to dying and death [2]. After death, the individual's body and spirit are believed to be integrated after death and removing organs is perceived to disturb both, particularly from the chest as this is viewed as this has metaphorical significance. There is variation across Islamic countries, such as Iran brain death is not culturally accepted [3]. However, in 
Saudi Arabia brain death is gaining social acceptance due to religious scholars increasing awareness about organ donation $[4,5]$.

Although Donation after Brain Death (DBD) is debated in some countries, in other countries it is accepted as Donation after Circulatory Death (DCD) is illegal. Donation after Circulatory Death is legally forbidden in Finland, Germany, Poland, Portugal and Luxembourg [6]. In Israel, brain death is only accepted with the use of electronic equipment as opposed to reliance on doctors, as decided upon after a rabbinical debate in 2008 [7]. In 2011, debate sparked again after the death of a famous football player in Israel, where it was concluded that death was defined as the cessation of breathing but did not include the continuation of breathing on a respirator, this was considered a 'breakthrough decision' [8].

In general, across countries with transplant programmes, social, religious, cultural, legal and historical norms and constructs accept the principle of transplantation as it adheres to the notion of giving and helping others. However, these constructs can influence the extent to which brain death or circulatory death in organ donation is accepted and could influence organ donation decisions. There are multiple views of what constitutes a 'good death' or the point at which a person is 'really dead'. In turn, these factors may be affected by the perceptions of the connectivity of the body and soul upon death and cultural death practices.

\section{Cross-cultural views toward the deceased body in organ donation}

Morgan et al. [1] conducted a systematic review of ethnic minority community attitudes toward deceased organ donation in the UK and North America [1]. They found a degree of uncertainty of religious perspectives toward body totality after death but this was of particular concern to those of Islamic faith but was an issue that arose across other religious groups. Morgan et al. suggested bodily concerns were influenced by cultural traditions, which were intertwined with religious scripture. Across the studies reviewed, there were fears and concerns about the body being cut and perceptions about this being unacceptable were more likely among ethnic minority groups.

Internationally, cultural and religious norms regarding the deceased body that hinder organ donation are: the sacredness of the deceased body [9]; the need for body totality upon death [10-19], a belief the organ will not be used beneficially [20] the importance of burial customs [10,21-23], fear of disfigurement of the body [23,24] and fear of missing organs affecting incarnation [25]. Bodily integrity has been found to be a significant predictor in the decision to donate organs [26].

There is a dearth of literature that represents the views of the Polish community outside of Poland toward organ donation. The literature on organ donation in Poland has shown that the public have positive attitudes toward organ donation but there is a lack of understanding of the organ donation process [27-30]. Over the past decade, in the UK Polish migrants are the fastest growing community and the Census (2011) reported Polish to be the second common language spoken in the UK [31]. In a UK setting, the views of Polish migrants toward organ donation were explored. The findings in the present paper are from a wider study that examined the perceptions of deceased organ donation, religion and the Maussian gift [32]. This is the first study of its kind in the UK and this paper outlines the findings of the perceptions toward the body after death, life after death and death practices.

\section{Methods}

As the study was explorative, a grounded theory methodology was used and a qualitative approach was taken for the study. A qualitative approach enables the exploration of people's views, attitudes and experiences. There were 31 participants who took part in one-to-one or small focus group interviews. Interviews lasted approximately an hour and a half and were conducted either at the University of Bedfordshire in Luton or at the participant's home. The majority of the interviews were in English and 1 focus group and 7 interviews were in Polish. A Polish interpreter led the interview with translated questions in an interview guide. The researcher (CS) was present and could listen to the interview through a real-time Polish interpreter who repeated the participant's responses in English. The interviews were recorded with permission from the participants and were transcribed. Transcripts were coded and analysed using grounded theory methods. The data was collected during a 6 month period in 2012 .

\section{Sample}

Inclusion criteria was participants were from the post-2004 and post-war Polish migration waves and lived in the Luton and Dunstable area. Sampling for the study occurred in three phases, the first sample was English-speaking Poles who were recruited through the University of Bedfordshire and were students or staff. The second sample was Polish migrants that were non-English speakers, worked in a lowskilled job or had a young family whilst living in the UK. The third sample was post-war migrants as this is a long-standing community in the area.

\section{Findings}

The key areas that arose when exploring the theme of the body in deceased organ donation were: body after death; life after death and death practices. The findings are reported as follows (Table 1):

\begin{tabular}{|l|l|}
\hline Majority & $\mathbf{1 5}$ participants \& above \\
\hline Many & 10 participants \& above \\
\hline Some & 5 participants \& above \\
\hline Minority & Below 4 Participants \\
\hline
\end{tabular}

Table 1: Frequency of expressed views.

\section{Body after death}

\section{Body totality}

The majority of participants believed an individual does not require organs after he or she has died as someone else could benefit from them, therefore the organs should be removed for transplantation purposes.

'[W]e won't after our death, we won't need them anyway... we might as well give them to somebody who will need them...towards helping other people.' (Post-2004, Male, Student and Teacher, 25)

'Some of them [family members] are thinking about destroying the body that the son or daughter or whoever doesn't look normal, but I think that when they realise that they are helping someone, they might be ok with that.' (Post-2004, Female, Vet Technician, 28) 
Citation: Sharp C, Randhawa G (2016) Cultural Attitudes towards Death Practices, the Body after Death and Life after Death in Deceased Organ Donation - A UK Polish Migrant Perspective. J Palliat Care Med 6: 262. doi:10.4172/2165-7386.1000262

Page 3 of 7

'[O]ur religion teaches us that our body is only on Earth, and in essence it isn't useful to us forever, and that it is (only) needed on Earth.' (Post-2004, Female, Personal Shopper, 29)

Two participants further argued this point as they suggested that the body does not need to be whole upon death as accidents can happen in a person's life time that means that a person would die with limbs or organs missing that he or she was born with that would not have effect on the 'soul' after death.

In Catholicism in what I know, the body is just temporary, it is the soul that what matters, so what happened to those who had car accidents and lost hands, legs. I don't think it would, need your whole body to be saved after you die.' (Post-2004, Male, Student and Bar Worker, 24)

A minority of participants suggested people may prefer the body should be whole upon death.

'I know a few people who have said, I don't want anything taken out of my body, I just want to be buried as I am.' (Post-2004, Female, Student, 24)

'I don't like thinking about my body becomes resource you know, I'm not, after my death, my body won't even go cold and they would be start cutting out the bits that they want, I don't like this idea. You know, I'm not against organ donation, but I don't like the idea of my body being treated as a resource.' (Post-2004, Male, Student, 24)

\section{Life after death}

\section{Perceived Family's Perspective of the Body and Life after Death}

Some participants thought that the person would be 'living on' in another person and for two of the participants, it was argued that the family would not be able to say 'goodbye'.

'[T]here is a feeling that you say goodbye to someone that died, but then you can't really do it if you know that part of him or her is still alive in someone else's body, it doesn't give you the opportunity for full closure I don't think, so it's really difficult.' (Post-2004, Female, Student, 22)

I think maybe because from the religion point of view people think about the eternal life and this is may give them the opportunity to be you know, maybe an extension of life in someone else's body.' (Post-1989, Female, Teaching Assistant, 42)

Personality transference through organ transplantation was not viewed to occur by a minority of participants, but one participant highlighted that this is an issue that has been the content of television programmes in Poland.

'[T]here is programmes that claim that there is a part of that person that remains in that organ there was a programme about this guy who got the heart of this motorcyclist fanatic and all of sudden he needed more adrenaline in life and he started doing things that he would never dare to do because he never, he was a never a person who was up for bungee jumping or something but all of a sudden he needed more adrenaline and there is other things in history, where all of a sudden people are wanted to have different types of food and I don't know if that is true.' (Post-2004, Female, Student, 22)

A few of the participants said that the eyes and heart have no special meaning.
'[Y]our personality lies within your brain, and not your heart.' (Post-2004, Male, Warehouse Worker, 20)

\section{Death practices}

\section{Appearance in an Open-Casket Coffin}

For some of the participants the appearance of the body after donation was not a concern.

'[B]efore their body is actually shown it's been modified to put a lot of stuff inside, I don't know what kind of stuff, to actually make it look nice, so I don't think that would actually influence, well, it might if someone didn't know about it, they might think, "oh maybe if I donate all my chest would collapse and I would look really skinny or something", it might put somebody off but generally I wouldn't think would be a problem, most the people I think realise the bodies are being specially prepared to their best before they are shown to the other people.' (Post-2004, Male, Student and Bar Worker, 24)

\section{Funeral Arrangements and Place of Burying the Body}

Many of the participants said burials are traditional in Poland.

In Poland, it is usually about 2-3 days, because we don't burn the bodies, we just put them in the coffin and then put them in the cemetery...So, they'd have to be kind of 'fresh'!...Because of the funeral, when you have the funeral, the person is in the coffin and it is open so you see her or him...Because we don't have cremation, it's only something from a few years ago.' (Post-2004, Female, Administrator, 30)

'Well in Poland, the funerals are really quick and in England, they are not, it's at least two weeks here before you can bury someone so I would say that it doesn't make any difference at all (to organ donation).' (Post-war, Female, Retired, 62)

A minority of participants suggested the body of the individual could be returned to Poland in order for the family to visit the grave on All Souls Day in November.

'[T]here is a tradition of visiting the graves, eve like we just had the first of November...it can be a problem in a certain respect' (Post-2004, Female, Housewife, 32)

A minority of participants argued the arrangement of the funeral could affect the family's decision to donate.

I'm not sure if it deters people or how it works in the UK, but if you decide to donate your organs... the problematic thing is to arrange the funeral, because they have to wait and all the procedures from the hospital to take your body and to do the funeral as well. It is very problematic, the majority of people are Catholic, so they want to organise the funeral in the few next days after you die, so it might be quite problematic.' (Post-2004, Female, Student, 22)

I believe that people in Poland and they have some die in England, they want the body to go back to Poland and do the funeral for the family and for themselves, I believe that if I would die, that they would think that I would not want to donate because I have haven't seen him for a while, I want him home, as he left Poland, I won't give any part of his body to anybody in England, maybe something like this.' (Post-2004, Female, Housewife, 29) 


\section{Discussion}

\section{Cultural death practices}

The importance of ritualised behaviour around death is emphasised by anthropologists Richardson and Banbury [33,34]. Richardson [33] analysed the history of death rituals and found that the protection of the body resonates throughout historic death customs. The cadaver is no longer a person and there is the expectation from the family that the body will be treated with care and respect by the health care professionals [33]. Banbury [34] argued that in modern society, death rituals bring families close together and are 'processual' (p.113) where the deceased and the relatives are undergoing transformations into their new roles within the family [34].

Funerals within Polish culture are quickly organised, with relatives who may have left Poland to visit their home country to attend the funeral. The deceased are buried in graveyards in Poland, therefore it was assumed the relative's deceased body will be sent back to Poland and buried near their family who would visit the grave on All Souls Day. One participant explained the deceased are buried quickly due to the superstition that delaying burial could lead to the deceased taking someone with them. Overall, cultural death rituals were not viewed to be hindered by the organ transplantation process.

The belief that organ transplantation does disturb traditional death rituals has been found in other studies. In Morgan et al.s [22] study that compared the views of Black Caribbean migrants in the UK to citizens in Barbados toward organ donation, it was found participants wanted their body to be buried 'whole' in the Caribbean or in a Caribbean style funeral in the UK [22]. Morgan et al. suggested burials and funerals symbolised the reconciliation of their divided identity in their life [22]. Randhawa outlined within certain Buddhist groups, there is a shared concern about 'disturbing the body in the hours after death' and this could impact upon decisions to donate organs [35]. Randhawa also argued the removal of organs from a relative whose family believe in the afterlife and immortality of the soul perceive organ donation to contradict these beliefs [35]. Families who hold these beliefs should be dealt with in a sensitive manner by health care professionals. In Japan, Lock [36] in Twice Dead, found Buddhism supports organ donation on the basis that this form of treatment saves lives [36]. However, Japanese Buddhists were not comfortable with the notion of the 'gift of life' as within Buddhist culture, reciprocity was embedded in tradition. In Japan, death is an event that is socially determined and not a specific moment and the way in which the spirit and body are perceived makes autopsy and brain death criteria controversial [36].

In a recent systematic review, Ralph et al. reviewed family perspectives on deceased organ donation [37]. They found 7 themes: comprehension of sudden death; finding meaning in donation; fear and suspicion; decisional conflict; vulnerability; respecting the donor and needing closure. Respecting the donor through preservation of the totality of the body was part of the donor families' decision making about organ donation. This could link with cultural death rituals in that the family may want to respect the deceased body by undertaking the rituals and the perception of whether the body needs to be whole could impact upon the decision to donate.

The participants in the present study suggested Polish funeral traditions would be adhered to as the body would be sent back to Poland to be buried and did not perceive donation to significantly interfere with this process. Quick funeral arrangements are practiced by other cultural groups such as Jews and Muslims that require the body to be buried within 24 hours of death. The transportation of the body highlighted by the participants occurs in other ethnic groups such as British Muslims born overseas as the family prefer the body to be buried close to other deceased family members [35]. Religious death rituals differ for Hindus and Sikhs where the body is washed and dressed by close relatives, then viewed by close relatives and friends before being cremated soon after death [35]. This illustrates that different religious and cultural practices can influence organ donation in terms of the perception families may have on how far traditional rituals can be adhered to and the appearance of the body during these rituals may be of concern to relatives.

\section{Gnosticism: The separation of the body and 'self' after death}

In the present study, it was commonplace to hold the view that the body was not needed after death and others could benefit from the organs from a deceased person, particularly when referring to the donation of one's own body posthumously. Catholicism supported organ donation through the teachings of loving and helping others. Polish Catholic beliefs contributed toward the view that the body is not required after death, in turn it was viewed there was little need for body totality for death customs. This may not be surprising as Bowman and Richardson [2] highlighted the role Christianity plays in medicine and in the case of organ donation, the body and mind separating upon death defines death and the person is no longer residing in the body.

In addition, the Polish religious and cultural belief that the body is not required after death could be explained by gnostic attitudes toward the body and the 'self' through the Cartesian philosophy [38]. Gnosticism 'seeks liberation of the true self from the body' where the 'true self resides in a disembodied mind or consciousness' where 'Body parts have no significant value.' Cartesian philosophy purports a separation between the 'self' and the 'body' and the body upon death is perceived as a 'resource'. Therefore, in the present study, the participants did not view there to be value in keeping the body whole as a deceased person's organs transform from functioning and living matter keeping the individual alive to body parts that are resources to treat others with organ failure. However, the notion of the body becoming a resource after death was referred to by one participant who was uncomfortable with this idea and lead to him opposing organ donation.

\section{Embodiment: The intrinsic relationship of the body and 'self'}

For some participants, there was a perception that an individual's 'spirit' (self) was to 'live on' in other people if he or she donated posthumously. This contradicts the idea of Gnosticism and Cartesianism as here the self exists in the body parts and is not separated. Therefore, Campbell argues this to be 'embodiment' where there is an 'intrinsic relationship of the body and self' and is part of Christian rhetoric. This idea of an intrinsic relationship between the body and self did not apply to specific organs or tissue being donated but to the suspension of the deceased individual's existence of the 'self' through any organ donated. The notion of an embodiment was a theme that arose when participants were discussing the donation of their relative's organs and the fear that this could lead to the relative 'living on' in others and in turn being unable to say 'goodbye' to their relative. Ralph et al. [37] in their systematic review highlighted the importance of needing closure for the families may contribute toward the reticence to donate if there is a perception that the relative's 'self' 
will live on as it could make it difficult for the family to have closure [37].

The notion of the deceased relative 'living on' in the recipient has been reported in previous literature [39,40]. Fox and Swazey found families that believe by donating organs, part of the person lives on can be important in the decision make process about deceased organ donation [39]. From a USA study with organ donor families, it was found $68 \%$ believed that their deceased relative would 'live on' in someone else [40]. The notion of the donor 'living on' in the recipient connects with Mauss's 'spirit of the gift' and Malinowski's hau, where the gift has a 'hold' over the recipient as part of an identity had transferred with the item. The concept of 'living on' has been found in previous research, such as Sque and Payne [41] who found if an individual has an unsuccessful transplant, there may be a sense of loss felt by the donor families and recipient, this was thought to illustrate an unconscious exchange where the donor's personhood was transferred in the organ, especially an organ such as the heart [41].

Sque and Payne found it was difficult for families to donate some body parts as they have symbolic meaning, such as the corneas as eyes were seen as the windows to the soul [41]. This phenomenon has been cited as a barrier in the donation of certain organs in some cultural and religious groups [23,42-44]. However, in the present study, a minority of participants held the gnostic attitude through the Cartesian philosophy regarding the eyes and heart as not having 'special meaning' as the 'self' has been liberated and separated from the 'body' upon death.

Families that believe by donating organs, part of the person lives on can be fundamental in the decision making process [39]. Batten and Prottas's conducted a study with organ donor families and found that $68 \%$ believed that their deceased relative would live on in someone else [40]. Healy explained that this phenomenon is in journalistic literature and organ donation professionals in America use this notion as a way of recruiting organ donors [45].

\section{Embodiment and Gnosticism in the bereavement process}

The family must make the decision to donate or not to donate a relative's organs at an emotionally charged time and it has been demonstrated religious, cultural and social norms play a role in the perception of death, the separation of the body and self after death and the need for body totality. The application of Gnosticism and embodiment may be fluid and dynamic within the different stages of bereavement.

Sque and Payne purported the bereavement stages to be: recalling 'the last time we were together'; informing 'finding out something is wrong'; hoping 'waiting for a diagnosis'; realising 'becoming aware things are going wrong, realisation of death'; deciding 'confirmation of brain stem death, donation decisions'; parting 'saying goodbye' and coping 'dealing with grief and donation' (p.1361) [41].

Deciding: Social, cultural and religious beliefs of the deceased body, attitudes toward organ donation and the need for body totality could influence the decision for the family to give permission for the relative's organs to be donated. From a gnostic perspective, if the family believe that there is a separation between the relative's 'self' from his or her 'body', the decision to donate could be influenced by the view the body is not needed by the individual any longer and could be used to help others, similar to the view the participants held in the present study. However, social, cultural and religious norms that view the body through an embodiment lens where the body and the self are not separated could inhibit the decision to donate organs. For example, Sque et al. [41] found that among bereaved families who declined permission for organ donation, there was the perception that the deceased had suffered enough and should not go through any more [46]. This implies the 'self' resides within the body as the 'self' would be experiencing the organ transplant surgery. In addition, religious and cultural norms that support incarnation [47] may feel that the body and the 'self' are intertwined and removing the organs affects the incarnation process as the body is not whole as part of the body is residing in another person and could delay the incarnation process.

Parting: Within the parting stage, there could be 'magical thinking' about the removal of a relative's organs. Individuals may think in a fantasy-type way about what will happen to the organs once transplanted in the recipient and what has happened to the 'self' of the individual once they have died. In turn, this could lead to families finding it difficult to say goodbye if part of their relative's 'self' is perceived to be still in existence and for the embodiment paradigm to influence views toward the donated organs. Sanner [47] found this in her study in Sweden where she used the idea of 'magical thinking' where 'Magic presupposes that an object or a person can be influenced by supernatural forces, not by natural laws' (p.1497) and this affects how people feel about the transference of the deceased's qualities into another person through their organ. She explained that this 'magical thinking' is common, even in today's Westernised society, citing superstition as an example. The participants in the study suggested that life is prolonged in another person [47]. Later, Sanner [47] argued bereaved families may find it difficult distinguishing between the living and the dead person [25].

Haddow [48] interviewed Scottish donor families on their views of death, the dead body, relationships with the deceased and whether these views influenced the decision to donate. Haddow suggested the family has to change their view of their relative's body as he or she is no longer alive and that this adjustment can have an impact on whether the body and 'self' are seen to be connected and shape perceptions of organ donation. Haddow's view of embodiment may explain how the family has to adjust their views of their loved one's body to no longer being alive. She explained that the Cartesian view of embodiment is linked with a detachment where the dead person is no longer attached to their body. However, from a holistic perspective, there was a view that the living person and the dead body were connected. Haddow found that families considered the embodiment of the newly deceased person as a mix of Cartesian and holistic, in a number of ways such as concern for the body's integrity and the identity of the living person. She created the following table to illustrate the connection between death, embodiment and organ donation [48] (Table 2).

\begin{tabular}{|l|l|l|l|}
\hline $\mathbf{1}$ & Non-awareness of death & $\begin{array}{l}\text { Non-seperation of } \\
\text { Body/Self }\end{array}$ & $\begin{array}{l}\text { Body } \\
\text { Immortality }\end{array}$ \\
\hline 2 & Awareness of Death & $\begin{array}{l}\text { Non-Seperation } \\
\text { Body/Self }\end{array}$ & $\begin{array}{l}\text { Body } \\
\text { Immortality }\end{array}$ \\
\hline 3 & Awareness of Death & $\begin{array}{l}\text { Non-Seperation } \\
\text { Body/Self }\end{array}$ & $\begin{array}{l}\text { Fear } \\
\text { Mutilation }\end{array}$ \\
\hline 4 & Awareness of Death & Seperation of Body/Self & No concern \\
\hline
\end{tabular}

Table 2: Death, embodiment and organ donation.

What can be learned from Haddow's table, which can be applied to the present study, is how the body is generally viewed by the 
participants. If this table represented a continuum, the majority of participants would be classified in section iv as many said 'why not?' to donation as the individuals themselves did not need their body after death. This illustrates a Cartesian view of the body where there is a perceived separation of the body and self, or body and soul, upon death and the body is no longer required. However, when considering the donation of a relative's organs, the view of the body and self may be mixed between level 'iv', where the person is believed to have gone to Heaven and the level 'iii' as it may be difficult for families to distinguish between the newly-dead person and their living identity, taking a holistic embodiment perspective on the body.

\section{Cultural, religious and social norms}

Across societies, religions and cultures, the body is regarded differently in its need after death and the perception of the connectivity between the body and the 'self'. From a Polish cultural perspective, there were fewer concerns surrounding body totality and the need for organs after death and could be attributed to religious and cultural perceptions of the connectivity between the body and self upon death and of the deceased body. The findings from the present study demonstrate the differences between the perceptions of the body when considering organ donation for oneself or for providing permission for a relative's organs to be donated. The family experiencing the bereavement process go back and forth between the separation of the body and self and the intertwining of the body and self after death and perceptions of whether the deceased relative's 'spirit' 'lives on' within the organ and how this could affect decisions about giving permission to donate a relative's organs. When an individual is considering the donation of organs posthumously for oneself, the separation of the body and self in addition to the Catholic teachings of helping others lead to the view that one should donate organs as the organs can prolong life in another person.

The study highlighted deceased organ donation was not perceived to have an impact on the pragmatic and traditional practices of funerals and burials within Polish culture. Participants believed that the aesthetic appearance of the body after the removal of organs is overcome by transplantation surgeons who could add structure to the body or the casket would be closed at the funeral. However, a review of literature on organ donation has shown that religious practices that have open casket burials could lead to an increase in an unwillingness to donate due to fears that donation will delay funeral proceedings and that the absence of organs could influence the individual's quality of afterlife [26]. Lauri found burial traditions were a barrier to organ donation as there are notions as to what makes a decent funeral and when people are buried, body totality is common [18].

Approaching Polish families for consent for organ donation could be informed by the findings of the study. Healthcare professionals have little research to refer to on the perceptions the Polish community have on the conceptualisation of the deceased body, life after death and death rituals. The findings of this study can inform healthcare professionals about the way that the body is viewed upon death, the potential impact that practical issues in the organisation of the transportation of the body and funeral could have on decisions to donate and the challenges that families may feel if there is the perception their relative is 'living on' in someone else and cannot say goodbye. In approaching discussions with families, healthcare professionals can be better prepared about the cultural issues and questions that may arise.
From a healthcare professionals' viewpoint, it can be taken into account that for organ transplantation there are two practical challenges associated with Polish funeral and burial rituals suggested by participants: quick arrangement of funerals and the transportation of the body back to Poland for burial. The need for quick transportation of the body and arrangement of the funeral if taking place in Poland could potentially impact upon the family's decision to donate if it is perceived the removal of organs could delay the proceedings. However, participants did acknowledge that if a person is buried in the UK, that it is not possible for funerals and burials to be arranged quickly. Therefore the place where the deceased person is buried could impact upon decision to donate.

\section{Limitations}

The present study was conducted with a small sample of participants, however according to grounded theory methodology theoretical saturation was reached that led to the cessation of data collection. The data was collected in Luton and Dunstable and the generalizability and extrapolation of findings to communities across the UK could be limited.

\section{Conclusion}

The present study found organ donation was supported by participants as the body is not needed by the deceased individual upon or after death. The continuation of the self or 'spirit' was viewed to 'live on' in the recipient and could impact upon the family's ability to say goodbye to their deceased relative. Depending on the country the deceased individual will be buried in presents different challenges to the practical arrangements of the funeral or if necessary, the transportation of the body and could influence the decision to donate. These findings could be applied to a clinical setting to improve the cultural awareness that healthcare professionals have regarding Polish attitudes toward the conceptualisation of the deceased body, perceptions of life after death and the impact of the practical challenges of the organisation of death rituals.

\section{References}

1. Morgan M, Kenten C, Deedat S, Donate Programme Team (2012) Attitudes to deceased organ donation as a donor among minority ethnic groups in North American and the UK: A synthesis of quantitative and qualitative research. Ethn Health 18: 367-390.

2. Bowman KW, Richard SA (2003) Culture, brain death, and transplantation. Prog Transplant 13: 211-215.

3. Dehghani SM, Gholami S, Bahador A, Nikeghbalian S, Eshraghian A, et al. (2011) Causes of organ donation refusal in southern Iran. Transplant Proc 43: 410-411.

4. Saudi Centre for Organ Transplantation (SCOT) (2012) Organ donation and transplantation in the Kingdom of Saudi Arabia 2011. Saudi J Kidney Dis Transpl 23: 1118-1122.

5. Habib K (2013) Organ donation gaining wide acceptance among Saudis, Arab News.

6. Dominguez-Gil B, Haase-Kromwijk B, Van Leiden H, Neuberger J, Boene L, et al. (2011) Current situation of donation after circulatory death in European countries. Transpl Int 24: 676-686.

7. Shtrauchler N (2009) Organ donation to get halachic approval.

8. Lev D (2011) Rabbi's Organ Donation Controversy Resurfaces: INN Review.

9. Al-Khawari FS, Stimson GV, Warrens AN (2005) Attitudes toward transplantation in the UK: Muslim Indo-Asians in West London. Am J Transplant 5: 1326-1331. 
Citation: Sharp C, Randhawa G (2016) Cultural Attitudes towards Death Practices, the Body after Death and Life after Death in Deceased Organ Donation - A UK Polish Migrant Perspective. J Palliat Care Med 6: 262. doi:10.4172/2165-7386.1000262

Page 7 of 7

10. Hayward C, Madill A (2003) The meanings of organ donation: Muslims of Pakistani origin and white English nationals living in North England. Soc Sci Med 57: 389-401.

11. Alden DL, Cheung AH (2000) Organ donation and culture: a comparison of Asian American and European American beliefs, attitudes, and behaviors. J Appl Soc Psychol 30: 293-314.

12. Lam WA, McCullough LB (2000) Influence of religious and spiritual values on the willingness of Chinese-Americans to donate organs for transplantation. Clin Transplant 14: 449-456.

13. Cheng B (2005) An overview on attitudes towards organ donation in Hong Kong. Hong Kong J of Nephr 7: 77-81.

14. Irving MJ, Jan S, Tong A, Wong G, Craig JC, et al. (2014) What factors influence people's decision to register for organ donation? The results of a nominal group study. Transpl Int 27: 617-624.

15. Pan X, Liu L, Xiang H, Ding C, Ren L, et al. (2014) Current attitudes toward organ donation after cardiac death in northwest China. Chin Med J (Engl) 127: 835-838.

16. Holman A, Karner-Hutuleac A, Ioan, B (2013) Factors of the willingness to consent to the donation of a deceased family member's organs among the Romanian urban population. Transplant Proc 45: 3178-3182.

17. Irving MJ, Tong A, Jan S, Cass A, Chadban S, et al. (2012) Community attitudes to deceased organ donation: a focus group study. Transplantation 93: 1064-1069.

18. Lauri MA (2006) Attitudes towards organ donation in Malta in the las decade. Malta Med J 18: 25-29.

19. Woo KT (1992) Social and cultural aspects of organ donation in Asia Ann Acad Med Singapore 21: 421-427.

20. Tumin M, Noh A, Jajri I, Chong CS, Manikam R, et al. (2013) Factors that hinder organ donation: religio-cultural or lack of information and trust. Exp Clin Transplant 11: 207-210.

21. Sheikh A, Dhami S (2000) Attitudes to organ donation among South Asians in the UK. J R Soc Med 93: 161-162.

22. Morgan M, Adams OP, Seed PT, Jones R (2010) Ethnicity and attitudes to deceased kidney donation: a survey in Barbados and comparison with Black Caribbean people in the United Kingdom. BMC Public Health 10: 266.

23. Exley C, Sim J, Reid N, Jackson S, West N (1996) Attitudes and beliefs within the Sikh community regarding organ donation: a pilot study. Soc Sci Med 43: 23-28.

24. Altraif IH, Al-Sebayel MI, Nondo H (1996) Knowledge and attitude towards organ donation among Males in Riyadh, Saudi Arabia. Saudi J Kidney Dis Transpl 7: 135-138.

25. Sanner MA (2006) People's attitudes and reactions to organ donation. Mortality 11: 133-158.

26. Radecki CM, Jaccard J (1997) Psychological aspects of organ donation: a critical review and synthesis of individual and next-of-kin donation decisions. Health Psychol 16: 183-195.

27. Perenc L, Radochonski M, Radochonski A (2012) Knowledge and attitudes of Polish university students toward organ donation and transplantation. Psychol Health Med 17: 667-673.

28. Jakubowska-Winecka A, Rowiński W, Włodarczyk Z, Wójtowicz S (2006) Extreme attitudes toward organ transplantation: how do supporters and opponents of this method of treatment differ in Poland? Transplant Proc 38: 111-113.

29. Kubler A, Lipinska-Gediga M, Kedziora J, Kubler, M (2009) Attitudes to brain death and organ procurement among university students and critical care physicians in Poland. Transplant Proc 41: 1473-1476.

30. RowiÅ,ski W, Paczek L (2002) Organ transplantation in Poland. Transplant Proc 34: 537-538.

31. Office for National Statistics (2011) 2011 Census: Quick Statistics for England and Wales.

32. Mauss M (2002) The Gift: The form and reason for exchange in archaic societies, Abingdon: Routledge.

33. Richardson R (2000) Death, Dissection and the Destitute, Chicago: University of Chicago Press.

34. Banbury M (1999) Representations of Death: A social psychological perspective, London: Routledge.

35. Randhawa G (2012) Death and organ donation: meeting the needs of multiethnic and multifaith populations. Br J Anaesth 108 Suppl 1: i88-91.

36. Lock M (2002) Twice Dead: Organ Transplants and the Reinvention of Death, Berkeley: University of California.

37. Ralph A, Chapman JR, Gillis J, Craig JC, Butow P, et al. (2014) Family perspectives on deceased organ donation: thematic synthesis of qualitative studies. Am J Transplant 14: 923-935.

38. Campbell CS (1998) Religion and the body in medical research. Kennedy Inst Ethics J 8: 275-305.

39. Fox RC, Swazey JP (2002) The courage to fail: A social view of organ transplants and dialysis (New Edition), Transaction Publishers: New Brunswick.

40. Batten HL, Prottas JM (1987) Kind strangers: the families of organ donors. Health Aff (Millwood) 6: 35-47.

41. Sque M, Payne SA (1994) Gift Exchange Theory: a critique in relation to organ transplantation. J Adv Nurs 19: 45-51.

42. Verble M, Worth J (2000) Fears and concerns expressed by families in the donation discussion. Prog Transplant 10: 48-55.

43. Ahmed W, Harris S, Brown E (1999) Attitudes to organ donation among South Asians in an English high street. J R Soc Med 92: 626-627.

44. Kaba E, Thompson R, Burnard P, Edwards D, Theodosopoulou E (2005) Somebody else's heart inside me: A descriptive study of psychological problems after a heart transplantation. Issues Ment Health Nurs 26: 611-625.

45. Healy K (2006) Last Best Gifts: Altruism and the Market for Human Blood and Organs, Chicago and London: The University of Chicago Press.

46. Sque M, Payne S, Macleod Clark J (2007) Gift of life or sacrifice? Key discourses for understanding decision-making by families of organ donors. In M. Sque and S. Payne (eds) Organ and tissue donation: an evidence base for practice. Berkshire, UK: Open University press.

47. Sanner MA (2001) Exchanging spare parts or becoming a new person? People's attitudes toward receiving and donating organs. Soc Sci Med 52: 1491-1499.

48. Haddow G (2005) The phenomenology of death, embodiment and organ transplantation. Sociol Health Illn 27: 92-113. 